\title{
Análisis de la contaminación microbiológica (coliformes totales y fecales) en el río Huaura - 2018
}

\section{Analysis of microbiological contamination (total and fecal coliforms) on the Huaura River $-2018$}

Anthony Apolinario Cortez Lázaro ${ }^{1}$, Andy Paolo Santa Cruz Ventura ${ }^{1}$, Angel David Hernández Amasifuen ${ }^{1}$, José Luis Romero Bozzetta

\section{RESUMEN}

Objetivo: Evaluar la calidad microbiológica del rio Huaura y reportar si está en condiciones óptimas para emplear en el riego de los cultivos de la zona. Materiales y Métodos: Las muestras se colectaron en cinco puntos de muestreo, se determinó el pH, temperatura y el número más probable de coliformes totales y fecales, coliformes termotolerantes y E. coli. Resultados: Todos los puntos de muestreo presentaron más de $1000 \mathrm{NMP} / 100 \mathrm{~mL}$ de coliformes totales, mientras que cinco de los cuatro puntos muestreados presentaron coliformes termotolerantes mayores a los $1000 \mathrm{NMP} / 100 \mathrm{~mL}$, estos niveles son mayores en los puntos que se encontraba más cercanos a la población, por ende, la zona con mayor proximidad a contaminación de los vecinos de los alrededores. Conclusiones: Las aguas del rio Huaura cercanas al puente Huaura presentan niveles superiores a los Entándares de Calidad Ambiental (ECAS) y Limite Máximo Permiciple (LMP) establecido por el Ministerio de Ambiente (MINAM) en el 2017, poniendo en peligro la salud de los pobladores por su directo consumo e indirecto al ser empleado para el riego de sus cultivos.

Palabras claves: Coliformes, E. coli, termotolerantes, Huaura, NMP.

\section{ABSTRACT}

Objective: to evaluate the microbiological quality of the Huaura river and report whether is in optimal conditions to be used for irrigation of the crops in the area. Materials and Methods: Samples were collected at five sampling points, the $\mathrm{pH}$, temperature and the most probable number of total and fecal coliforms, thermotolerant coliforms and E. coli were determined. Results: All sampling points presented more than $1000 \mathrm{NMP} / 100 \mathrm{~mL}$ of total coliforms, while five of the four sampled points showed thermotolarant coliforms greater than $1000 \mathrm{NMP} / 100 \mathrm{~mL}$, these levels are higher at the points that were closest to the population, therefore, the area with the closest proximity to contamination of the neighbors of the surroundings. Conclusions: The waters of the Huaura river near the Huaura bridge have higher levels in the ECAS and LMP established by the MINAM in 2017, endangering the health of the inhabitants due to their direct and indirect consumption when used to irrigate their crops.

Keywords: Coliforms, E. coli, thermolorants, Huaura, NMP.

\section{INTRODUCCIÓN}

El agua es un elemento vital para los seres vivos, por consiguiente, el acceso al agua potable es esencial para la vida, sin embargo, el crecimiento de la población, el incremento de la industrialización, la escasez de fuentes de agua para consumo libres de contaminantes, es decir, inocuas, constituye un problema que enfrenta la población peruana. El agua puede convertirse en un vehículo transmisor de diversas enfermedades ya que están expuestas a una amplia gama de factores que pueden alterar su calidad biológica (Tarqui et al., 2016); ocasionando cambios simples y complejos con diferentes niveles de intensidad, originando así una producción de aguas residuales de la industria minería y agricultura, entre otras. La contaminación fecal de las fuentes de aguas superficiales para abastecimiento de consumo humano es uno de los problemas más preocupantes en los países en vías de desarrollo. En las grandes ciudades esta contaminación se debe principalmente al vertimiento de los desagües sin ningún tratamiento. También se ha observado que la contaminación fecal es intensa en las zonas de arrastre provenientes de los corrales de engorde de bovinos y de las avícolas (OMS, 1996).

Las bacterias coliformes son indicadoras de contaminación fecal y, por lo tanto, de la posible presencia de otros patógenos como virus, bacterias, protozoos y fases enquistadas de metazoarios. Se asume que los indicadores y las bacterias patógenas pueden encontrarse juntos o estar relacionados, es recomendable seleccionar el indicador más adecuado a las condiciones locales. Ellas responden a factores ecológicos diversos, que influyen en su permanencia y sobrevivencia. Las bacterias coliformes fecales están adaptadas para vivir en el tracto gastrointestinal, considerado como su hábitat primario, aunque pueden sobrevivir en el agua residual y cuerpos acuáticos receptores, que son considerados hábitats secundarios (Ashbolt et al., 2001; Harwood et al., 2005; Savichtcheva y Okabe, 2006)

Perú enfrenta problemas de abastecimiento y contaminación de agua sobre todo en las zonas rurales o recientemente pobladas. En las zonas rurales, frecuentemente existen problemas de disponibilidad de agua, falta de potabilización y contaminación de agua, debido a que una parte de la población consume agua potable, otras se abastecen de agua que proviene de manantiales, ríos, arroyos, ojos de agua u otras fuentes naturales de agua, que están expuestas a partículas orgánicas e inorgánicas. (OMS. 1996). Un estudio realizado en hogares de niños menores de cinco años, mostró que el 38,3 \% de las muestras de agua tuvieron ausencia de coliformes totales y $E$. coli, siendo más afectados los hogares de la zona rural, en donde se observó que menos del $5 \%$ tuvieron agua libre de coliformes totales y E. coli. Existen escasos estudios que evalúan la calidad del agua en los hogares peruanos, por ello, la Dirección Ejecutiva de Vigilancia Alimentaria y Nutricional realizó la vigilancia bacteriológica del agua en algunos departamentos con mayor pobreza (Huancavelica, Cajamarca y Huánuco) (INEI, 2014).

La fuente continua está dada por la afluencia del rio Huaura en la Bahía de Carquin, adicionándose a ella la descarga de efluentes domésticos de Huaura y Carquin. El volumen de aguas servidas vertidas a través del rio Huaura alcanza el volumen de $288 \mathrm{~m}^{3}$ por año, conteniendo una carga orgánica expresada en DB05 de 732,73 t/año. Esto se refleja en la alta concentración de bacterias coliformes tanto en verano como en primavera, donde los valores sobrepasan los límites permisibles según la Ley General de Aguas vigente en el 
país para la Clase IV, V Y VI, en aguas de contacto primario, aguas de zonas de pesca de mariscos bivalvos y de preservación de recursos acuáticos y pesca comercial; por lo tanto la calidad del agua de mar y los organismos de importancia comercial se ven afectados por los altos índices de contaminación microbiológica que es transportada por el Rio Huaura (Cuellar et al., 2014).

Por lo tanto, la presente investigación tiene como objetivo evaluar la calidad microbiológica del rio Huaura y reportar si el rio esta en condiciones óptimas para emplear en el riego de los cultivos de la zona.

\section{MATERIALES Y MÉTODOS}

La evaluación de la calidad microbiológica del agua del rio Huaura se realizó a finales del mes de noviembre y quince del mes de diciembre. El muestreo se realizó en 5 puntos en relación a los puntos de mayor afluencia y puntos destinados a canales de regadío, los cuales estuvieron separados 200 metros cada punto (Figura 1).

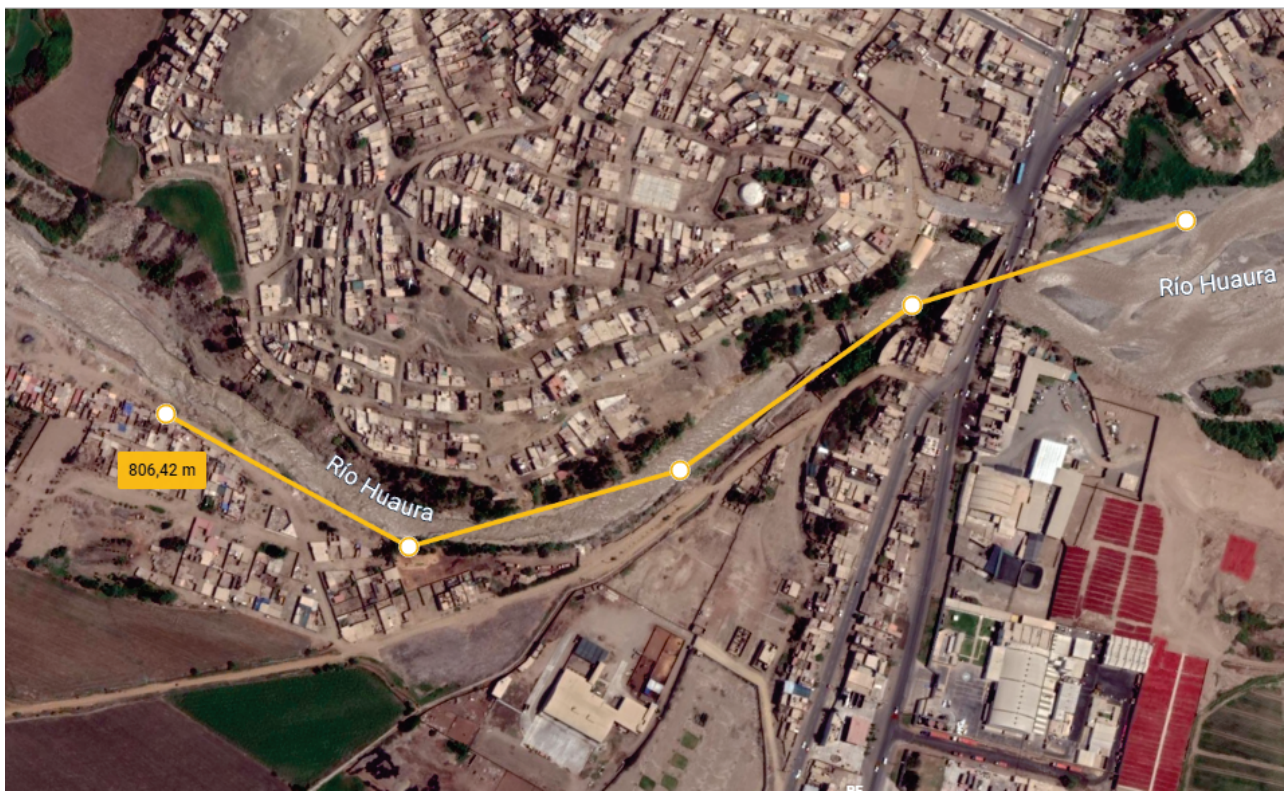

Figura 1 Ubicación de los puntos de muestreo del rio Huaura. Fuente: Google earth

Las muestras se colectaron en frascos estériles, y fueron trasladadas a los laboratorios multifuncionales de la Escuela Profesional de Biología con mención en Biotecnología, en la Universidad Nacional José Faustino Sánchez Carrión, Huacho, donde fueron incubadas antes de transcurrir 12 horas. Todas las muestras colectadas se mantuvieron en un recipiente a una temperatura promedio de $4^{\circ} \mathrm{C}$ durante el transporte. Así mismo durante la colecta se determinó la temperatura y el pH de cada punto de muestreo (Tabla 1).

Tabla 1

Caracteristicas climatológicas de las zonas de muestreo

\begin{tabular}{|c|c|c|c|}
\hline $\begin{array}{l}\text { Punto de } \\
\text { Muestreo }\end{array}$ & Localización & pH & Temperatura \\
\hline 1 & $\begin{array}{c}11^{\circ} 04^{\prime} 24^{\prime \prime} \mathrm{S} \\
77^{\circ} 35^{\prime} 50^{\prime \prime} \mathrm{W}\end{array}$ & 7,96 & $21^{\circ} \mathrm{C}$ \\
\hline 2 & $\begin{array}{l}11^{\circ} 04^{\prime} 28 " \mathrm{~S} \\
77^{\circ} 35^{\prime} 55^{\prime \prime} \mathrm{W}\end{array}$ & 7,94 & $20^{\circ} \mathrm{C}$ \\
\hline 3 & $\begin{array}{c}11^{\circ} 04^{\prime} 34^{\prime \prime} \mathrm{S} \\
77^{\circ} 35^{\prime} 58^{\prime \prime} \mathrm{W}\end{array}$ & 7,97 & $20^{\circ} \mathrm{C}$ \\
\hline 4 & $\begin{array}{l}11^{\circ} 04^{\prime} 38 \text { ' S } \\
77^{\circ} 36^{\prime} 04^{\prime} \mathrm{W}\end{array}$ & 7,95 & $21^{\circ} \mathrm{C}$ \\
\hline 5 & $\begin{array}{l}11^{\circ} 04^{\prime} 37^{\prime \prime} \mathrm{S} \\
77^{\circ} 36^{\prime} 10^{\prime} \mathrm{W}\end{array}$ & 7,93 & $21^{\circ} \mathrm{C}$ \\
\hline
\end{tabular}

La técnica de fermentación por tubos múltiples fue la adecuada para la evaluación (APHA, 2005), usando esta técnica el grupo coliforme se define como: bacterias Gram negativas, anaerobias facultativas, no esporuladas, en forma de bastón, fermentadoras de la lactosa con producción de gas y ácido en 48 horas a $35^{\circ} \mathrm{C}$ de temperatura. Los coliformes fecales fermentan lactosa con producción de ácido y gas a $44,5^{\circ} \mathrm{C}$. En esta técnica los resultados se expresan en términos de Número Más Probable (NMP) en $100 \mathrm{~mL}$.

\section{Prueba presuntiva de coliformes totales y fecales}

Para realizar esta prueba se usó caldo lauril triptosa en 15 tubos de ensayo conteniendo por dentro tubos Durham. Estos tubos se dividieron en tres series de 5 tubos, donde se adicionó los volúmenes de 10; 1 y 0,1 $\mathrm{mL}$. de cada punto muestreado, agitando o mezclando por inversión e incubando a $35+/-1^{\circ} \mathrm{C}$. A las 24 horas se observa turbiedad en el medio y/o producción de gas en el tubo Durham se procede a incubar nuevamente por 24 horas más para detectar los coliformes que son fermentadores lentos de la lactosa. Se tomaron como positivos aquellos tubos con presencia de turbidez y producción de gas al culminar las 48 horas.

Prueba confirmatoria para coliformes totales, fecales, termotolerantes y E. coli

En esta prueba son usados lo tubos positivos de la prueba presuntiva, para esto en caldo bilis verde brillante una o más asadas son resembradas, incubando a $36+/$ $1^{\circ} \mathrm{C}$ por 48 horas. La presencia de gas y turbiedad que aparezca en los tubos será considerada positiva la 
prueba de confirmativa de coliformes totales.

Para la confirmación de Escherichia coli se replicaron los tubos positivos de la fase presuntiva en caldo EC, incubando a $44,5+/-0.5^{\circ} \mathrm{C}$ por 48 horas. La turbiedad y producción de gas en los tubos dan a conocer que la prueba confirmativa es positiva para coliformes fecales, a la vez se resembró en agar eosina azul de metileno (EMB) a $35+/-1^{\circ} \mathrm{C}$ por 24 horas para convalidar la presencia de Escherichia coli. Las colonias que crecieron en el medio se le hicieron pruebas bioquímicas y coloración Gram para su confirmación (Figura 2).

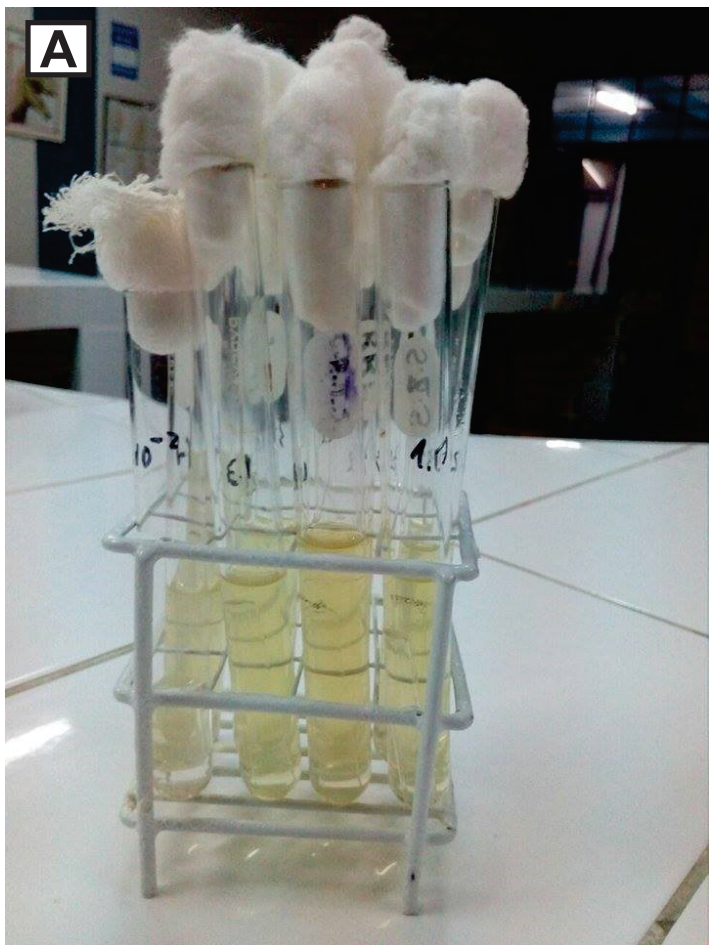

\section{RESULTADOS}

Todos los puntos de muestreo presentaron más de 1000 NMP/100 mL de coliformes totales. Mientras que cinco de los cuatro puntos muestreados presentaron coliformes termotolarantes mayores a los 1000 NMP/100 mL, estos niveles son mayores en los puntos que se encontraba mas cercanos a la población, por ende, la zona con mayor proximidad a contaminación de los vecinos de los alrededores (Tabla 2)

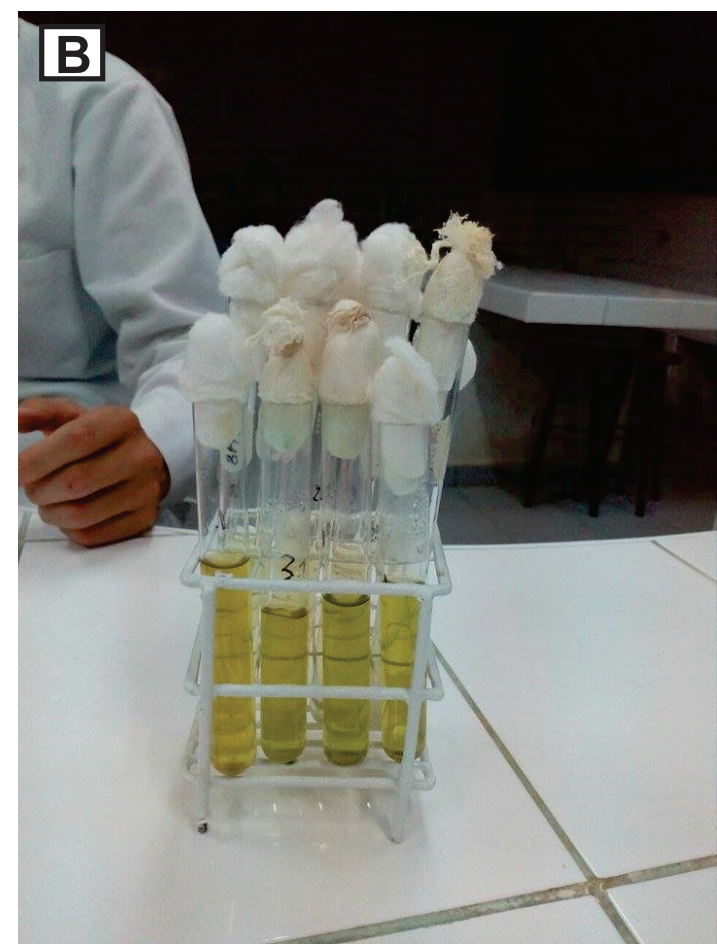

Figura 2 Tubos positivos con caldo Lauril triptosa que presentan turbidez y producción de gas (A). Tubos positivos con caldo verde billis brillante $(B)$.

Tabla 2

Promedio de la presencia de Coliformes en los cinco puntos de muestreo en el rio Huaura.

\begin{tabular}{ccccc}
\hline $\begin{array}{c}\mathbf{N}^{\circ} \text { de } \\
\text { Muestreo }\end{array}$ & $\begin{array}{c}\text { Coliformes } \\
\text { Totales } \\
\text { NMP/ 100mL }\end{array}$ & $\begin{array}{c}\text { Coliformes } \\
\text { Fecales } \\
\text { NMP/ 100mL }\end{array}$ & $\begin{array}{c}\text { Coliformes } \\
\text { Termotolerantes } \\
\text { NMP/ 100mL }\end{array}$ & $\begin{array}{c}\text { Escherichia } \\
\text { coli } \\
\text { NMP/ 100mL }\end{array}$ \\
\hline 1 & 1383 & 780 & 1070 & 692 \\
\hline 2 & 1275 & 692 & 780 & 453 \\
4 & 1383 & 692 & 1070 & 480 \\
\hline 5 & 1690 & 1070 & 1383 & 780 \\
\hline
\end{tabular}

\section{DISCUSIÓN}

Los alto niveles de coliformes presentes por cada $100 \mathrm{~mL}$ de agua del rio Huaura demuestra primeramente que no es apta para el consumo directo de los pobladores, acción que en muchos casos se presentan por pobladores de extrema pobreza, además de que ser necesario emplear mayores tratamientos que solo el empleo de desinfectantes, tal como afirma el Decreto
Supremo Nº04 - 2017 - MINAM que en los parámetros microbiológicos y parasitológicos los NMP/100 ml de Coliformes Totales para aguas que pueden ser potabilizadas con desinfección pueden ser hasta de 50 NPM/100 mL.

En el caso de parámetros destinado al riego de vegetales y bebida de animales, los niveles de coliformes termotolerantes son superiores a los permitidos para 
riego no restringido, es decir para cultivos que se consumen sin ser cocidos, como ejemplo las lechugas que se cultivan en zonas cercanas, además también supera para la bebida de animales tanto mamíferos como aves que los pobladores crían para consumo propio y ventas. Tal como afirma el Decreto Supremo $\mathrm{N}^{\circ}$ 004 - 2017 - MINAM que en los parámetros microbiológicos y parasitológicos los NMP/100 ml de Coliformes Totales para aguas destinado al riego de vegetales y bebida de animales, su límite máximo es 1000 NMP/100 mL.

Estos resultados permiten entender mejor los niveles contaminación microbiológica presentes en diferentes puntos del rio Huaura en relación a los últimos años que se vienen mostrando noticias e imágenes de las fuentes de contaminación directa a este rio por aguas residuales. Mostrándose niveles mas altos en los puntos de cercanos a orillas donde se encuentran los pobladores y también por las descargas de camales. Considerando también que el rio de Huaura es fuente de animales que pueden ser vectores de enfermedades, ya que existe niños que recorren y juegan en estas aguas, exponiéndose y poniendo en riesgo su salud. Además de que estas aguas sirven para el riego de los cultivos de los agricultores de la zona, los cuales en momentos han tenido que regar sus parcelas y siembras con aguas cubiertas por un color rojizo, con presencia de plumas y grasa. Por lo que existe una reducción en la calidad y precios de sus productos por los estándares de calidad, dificultando la venta de estos productos. (Huacho Portal, 2013; Cuellar y Navarro, 2016; Pineda et al., 2019).

\section{CONCLUSIÓN}

Las aguas del rio Huaura cercanas al puente Huaura presentan niveles superiores en los ECAS y LMP establecido por el MINAM en el 2017, poniendo en peligro la salud de los pobladores por su directo consumo e indirecto al ser empleado para el riego de sus cultivos.

\section{REFERENCIAS BIBLIOGRÁFICAS}

APHA (2005) Standard Methods for the Examination of Water and Wastewater. 21st Edition, American Public Health Association/American Water Works Association/Water Environment Federation, Washington DC.

Ashbolt, N., Gravow W. y Snozzi, M. (2001). Indicators of microbial water quality. In: Fewtrell, L. \& J. Bartram (Eds.). Water Quality Guidelines, Standards and Health. WHO, IWA Publishing, London, 289-316.

Cuellar, J. y Navarro, J. (2016). Niveles de contaminantes que afectan la calidad de aguas del Rio Huaura en su cuenca baja. Infinitum 6(2): $80-$ 89.
Cuellar, J., Flores, R. y Ventocilla, D. (2014). Niveles de contaminantes que afectan la calidad de aguas del rio Huaura. Programa Nacional de Ciencia y Tecnología Ambiental.

DECRETO SUPREMO Nº04-2017-MINAM, Diario Oficinal del bicentenario el peruano, Lima, Perú, 07 de junio de 2017.

Harwood, V., Levine, A., Scott, T., Chivukula, V., Lukasik, J., Farrah S. \& Rose, J. 2005. Validity of the indicator organism paradigm for pathogen reduction in reclaimed water and public health protection. Applied and Environmental Microbiology 71: 31633170.

Huacho Portal. 2013. La otra cara del rio Huaura: contaminación extrema. Recuperado el 7 de noviembre del 2019 de: http://huachoportal.blogspot.com/2013/10/la-otra-cara-del-riohuaura.html.

Instituto Nacional de Estadística e Informática (INEI). Evolución de la pobreza monetaria 2009-2013. Lima: INEI; 2014. [Internet]. Disponible en: D i s pon i b le e n : http://www.inei.gob.pe/media/cifras_de_pobreza/inf ormetecnico.pdf [Revisado el 10 de noviembre de 2019].http://www.inei.gob.pe/media/cifras_de_pobr eza/informetecnico.pdf

Ley $\mathrm{N}^{\circ} 28611$, Diario Oficial del bicentenario el peruano, Lima, Perú, 02 de junio de 2017.

OMS. (1996). La calidad del agua potable en América Latina. Ponderación de los riesgos microbiológicos contra los riesgos de los subproductos de la desinfección química. Washington D. C.: Ilsi Press.

Pineda A., Cortez A., Argüelles F., Hernández A., Santa Cruz, A., Romero L. \& Romero, Y. 2019. Calidad microbiológica de la laguna "La Encantada", Santa María - 2018. Big Bang Faustiniano 8(1): 49-52.

Savichtcheva, O. y Okabe, O. (2006). Alternative indicators of fecal pollution: relations with pathogens and conventional indicators, current methodologies for direct pathogen monitoring and future application perspectives. Water research 40 (4): 120 - 131.

Tarqui, C., Alvarez, D., Gómez, G. y Valenzuela, R. 2016. Calidad bacteriológica del agua para consumo en tres regiones del Perú. Scielo, 1, 9. 